\title{
Development of Chitosan-Based Surfaces to Prevent Single- and Dual-Species Biofilms of Staphylococcus aureus and Pseudomonas aeruginosa
}

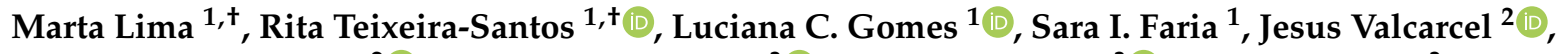

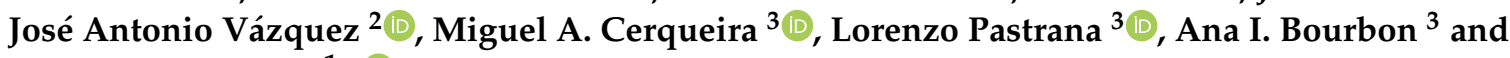 \\ Filipe J. Mergulhão $1, * \mathbb{E}$
}

Citation: Lima, M.; Teixeira-Santos, R.; Gomes, L.C.; Faria, S.I.; Valcarcel, J.; Vázquez, J.A.; Cerqueira, M.A.; Pastrana, L.; Bourbon, A.I.; Mergulhão, F.J. Development of Chitosan-Based Surfaces to Prevent Single- and Dual-Species Biofilms of Staphylococcus aureus and Pseudomonas aeruginosa. Molecules 2021, 26, 4378. https://doi.org/10.3390/molecules 26144378

Academic Editor: Cédric Delattre

Received: 31 May 2021

Accepted: 14 July 2021

Published: 20 July 2021

Publisher's Note: MDPI stays neutral with regard to jurisdictional claims in published maps and institutional affiliations.

Copyright: (c) 2021 by the authors. Licensee MDPI, Basel, Switzerland. This article is an open access article distributed under the terms and conditions of the Creative Commons Attribution (CC BY) license (https:// creativecommons.org/licenses/by/ $4.0 /)$.
1 LEPABE-Laboratory for Process Engineering, Environment, Biotechnology and Energy, Faculty of Engineering, University of Porto, Rua Dr. Roberto Frias, 4200-465 Porto, Portugal; up201604683@fe.up.pt (M.L.); ritadtsantos@fe.up.pt (R.T.-S.); luciana.gomes@fe.up.pt (L.C.G.); sisf@fe.up.pt (S.I.F.)

2 Grupo de Reciclado y Valorización de Materiales Residuales (REVAL), Instituto de Investigaciones Marinas (IIM-CSIC), C/Eduardo Cabello, 6, CP36208 Vigo, Galicia, Spain; jvalcarcel@iim.csic.es (J.V.); jvazquez@iim.csic.es (J.A.V.)

3 International Iberian Nanotechnology Laboratory, Department of Life Sciences, Av. Mestre José Veiga s/n, 4715-330 Braga, Portugal; miguel.cerqueira@inl.int (M.A.C.); lorenzo.pastrana@inl.int (L.P.); ana.bourbon@inl.int (A.I.B.)

* Correspondence: filipem@fe.up.pt; Tel.: +351-225-081-668

+ These authors contributed equally to this work.

\begin{abstract}
Implantable medical devices (IMDs) are susceptible to microbial adhesion and biofilm formation, which lead to several clinical complications, including the occurrence of implant-associated infections. Polylactic acid (PLA) and its composites are currently used for the construction of IMDs. In addition, chitosan (CS) is a natural polymer that has been widely used in the medical field due to its antimicrobial and antibiofilm properties, which can be dependent on molecular weight (Mw). The present study aims to evaluate the performance of CS-based surfaces of different Mw to inhibit bacterial biofilm formation. For this purpose, CS-based surfaces were produced by dip-coating and the presence of CS and its derivatives onto PLA films, as well surface homogeneity were confirmed by contact angle measurements, Fourier transform infrared spectroscopy (FTIR) and scanning electron microscopy (SEM). The antimicrobial activity of the functionalized surfaces was evaluated against single- and dual-species biofilms of Staphylococcus aureus and Pseudomonas aeruginosa. Chitosan-based surfaces were able to inhibit the development of single- and dual-species biofilms by reducing the number of total, viable, culturable, and viable but nonculturable cells up to $79 \%, 90 \%, 81 \%$, and $96 \%$, respectively, being their activity dependent on chitosan Mw. The effect of CS-based surfaces on the inhibition of biofilm formation was corroborated by biofilm structure analysis using confocal laser scanning microscopy (CLSM), which revealed a decrease in the biovolume and thickness of the biofilm formed on CS-based surfaces compared to PLA. Overall, these results support the potential of low Mw CS for coating polymeric devices such as IMDs where the two bacteria tested are common colonizers and reduce their biofilm formation.
\end{abstract}

Keywords: antibiofilm activity; chitosan; chitosan-polylactic acid surfaces; dual-species biofilms; implantable medical devices; polylactic acid surfaces; Pseudomonas aeruginosa; single-species biofilms; Staphylococcus aureus

\section{Introduction}

Implantable medical devices (IMDs), such as prosthetic joints and catheters, have been widely used in the medical field for both diagnosis and therapeutic purposes [1,2]. In recent years, the number of implanted medical devices has increased significantly with the aging population and the growing occurrence of comorbidities [3,4]. Although IMDs are 
essential for maintaining the life quality of patients, they are associated with serious clinical complications, including the occurrence of infections [5]. Implant-associated infections (IAIs) have an incidence between $2 \%$ and $40 \%$, depending on the type of medical device [6], and are responsible for prolonged hospital stays, increased costs, and high morbidity and mortality rates [7]. In the United States, these infections account for $60-70 \%$ of all healthcareassociated infections reported annually [4] and represent approximately $\$ 3$ billion of direct costs [8].

Most IMDs are susceptible to microbial adhesion and, consequently, biofilm formation, which is the leading cause of IAIs. A variety of pathogens can cause devicerelated infections, depending on the type of implantable device and the anatomical site of implantation [4,9]. Despite IAIs being often caused by Staphylococcus spp. [10], many other pathogens may be responsible for these infections, including Enterococcus spp. [11], Escherichia coli [12], Pseudomonas aeruginosa [13], and Candida spp. [14]. Once adhered to implant surfaces, microorganisms form biofilms, which protect them from the host immune response and the action of antimicrobial agents, contributing to the persistence and spread of infection $[15,16]$. Biofilms often harbor viable but nonculturable (VBNC) cells, which are living cells that have lost the ability to divide in media on which they normally grow. These cells have an intact membrane, undamaged genetic information, a lower metabolic rate, and higher physical and chemical resistance when compared to culturable cells [17]. Additionally, it has been shown that some pathogenic VBNC cells are not detected by standard methods and are not eliminated by antibiotic treatment, being able to resuscitate to a normal metabolic state and cause infection [18]. In the past decades, the increasing antimicrobial resistance has limited the efficacy of antibiotic treatment, contributing to biofilm development with consequent device failure and chronic infection [3,19].

The difficulties in treating established biofilms have prompted research on implant surfaces that resist microbial colonization and consequent biofilm formation. The strategies used to prevent microbial adhesion are based on coating IMDs with compounds that generate anti-adhesive/bacteria-repelling (e.g., polymers), contact-killing (e.g., antimicrobial peptides), or antimicrobial-releasing (e.g., metals and biocides) surfaces [3,20]. Despite the efforts to reduce the incidence of IAIs, most of the developed coatings exhibit low biocompatibility and toxicity for human cells [15], and their antimicrobial efficacy has not been completely proven.

Chitosan (CS) is a cationic polysaccharide obtained from chitin [21,22], which is commonly sourced from crustacean shells, mollusks, insects, and fungi [23], and converted into CS through partial deacetylation [24]. In the past years, CS has been introduced in the medical field due to its attractive intrinsic properties, namely high biocompatibility, non-toxicity, biodegradability, low allergenicity, and low cytotoxicity for human cells [25]. Furthermore, $\mathrm{CS}$ and its derivatives have a wide spectrum of antimicrobial activity against Gram-positive and Gram-negative bacteria, filamentous fungi, and yeasts, both in planktonic and sessile states [26]. Although the CS mechanism of action is not completely characterized, three main mechanisms were proposed for the inhibition of microbial growth: (i) cell membrane disruption, (ii) complexation with DNA, and (iii) metal chelation. The first mechanism is based on electrostatic interactions between the positively charged CS molecules (due to the amino groups of glucosamine) and negatively charged cell membranes (due to the presence of phospholipids with anionic phosphate groups), which change the permeability of cell membranes with consequent loss of intracellular content and cell death $[27,28]$. The second mechanism consists of the penetration of CS molecules into microbial cells and binding to DNA with subsequent inhibition of mRNA and protein synthesis [29]. In the third mechanism, CS molecules chelate metal ions (e.g., $\mathrm{Ca}^{2+}$ and $\mathrm{Mg}^{2+}$ ), damaging microbial cell walls $[27,30]$.

The antimicrobial activity of CS and its derivatives is dependent on a set of environmental factors, including the $\mathrm{pH}$, microorganism species, and their structural properties such as source, concentration, degree of deacetylation, and molecular weight $[27,31,32]$. Up to date, several studies have focused on CS efficacy to reduce biofilm formation on 
indwelling catheters [33-37]. Although results are encouraging, the employment of CS on IMDs remains understudied and the relation between CS chemical properties, in particular molecular weight, and its antibiofilm activity is not fully understood [31]. Hence, the present study aims to functionalize polylactic acid (PLA) surfaces incorporating chitosan with different molecular weights and evaluate their performance to prevent single- and dual-species biofilm formation by Staphylococcus aureus and Pseudomonas aeruginosa as they are common colonizers of implantable devices [38]. To the best of our knowledge, this is the first study that reveals the potential of CS-based surfaces of different Mw to reduce VBNC cells in multispecies biofilms associated with the medical field.

Polylactic acid (PLA) was the material chosen for this work because it is one of the most commonly used biodegradable polymers in clinical applications, including for the construction of IMDs [39,40]. This is mainly due to its biocompatibility, non-toxicity, and safe degradation products. Furthermore, the mechanical properties of PLA are similar to synthetic polymers and it has the advantage of the higher abundance and lower cost [41]. In the past years, several modifications using natural compounds, peptides, enzymes, metals, chelating agents, and antibiotics, have been introduced into PLA polymeric matrix to provide antimicrobial and antibiofilm properties [42].

\section{Results}

\subsection{Characterization of Chitosan and Its Derivatives}

Endoskeletons of the Loligo opalescences squid were processed through pre-optimized enzymatic and alkaline treatments [43] to extract chitosan. From this procedure, a highly purified $\beta$-chitosan ( $\beta$-CS) with $92 \%$ of deacetylation and a molecular weight $(\mathrm{Mw})$ of $294 \mathrm{kDa}$ was obtained. Subsequently, the native CS was depolymerized using sodium nitrite and generated three $\beta$-chitooligosaccharides with different Mw: CS1 of $186 \mathrm{kDa}, \mathrm{CS} 2$ of $129 \mathrm{kDa}$, and CS3 of $61 \mathrm{kDa}$ (Figure S1 in Supplementary Materials). Chitosan solutions at $0.5 \%(w / v)$ were then immobilized on PLA films by dip-coating.

\subsection{Characterization of Functionalized Surfaces}

Since it is known that surface properties influence the extension of cell adhesion and consequent biofilm formation [44,45], the four CS-coated PLA surfaces and control (PLA) were first analyzed concerning their hydrophobicity through water contact angle measurement using the sessile drop method (Table 1; Figure S2 in Supplementary Materials).

Table 1. Water contact angle values of polylactic acid (PLA) and chitosan (CS)-coated PLA surfaces.

\begin{tabular}{cc}
\hline Surfaces & $\begin{array}{c}\text { Water Contact Angle Values } \\
\text { (mean } \pm \text { SD) }\end{array}$ \\
\hline PLA & $69.53 \pm 1.2$ \\
B-CS-PLA & $37.01 \pm 1.1$ \\
CS1-PLA & $38.01 \pm 5.3$ \\
CS2-PLA & $38.93 \pm 2.7$ \\
CS3-PLA & $40.55 \pm 2.8$ \\
\hline
\end{tabular}

Considering that water contact angle values below $90^{\circ}$ indicate that a surface is hydrophilic [46], results demonstrated that both PLA and CS-PLA surfaces have a hydrophilic behavior. However, the immobilization of $0.5 \%$ CS $(w / v)$ solutions on PLA surfaces by dip-coating significantly decreased the PLA water contact angle by $40-50 \%$, which confirms the presence of CS on functionalized surfaces. Moreover, the molecular weight of CS did not influence the wettability of functionalized surfaces since the water contact angle remained at $40^{\circ}$.

The chemical modifications introduced on PLA surfaces after $\beta$-CS, CS1, CS2, and CS3 immobilization were evaluated by Fourier transform infrared spectroscopy (FTIR, Figure 1). From the analysis of the spectrum of the PLA surface, it was possible to observe the charac- 
teristic bands of PLA with high-intensity peaks represented at $1750 \mathrm{~cm}^{-1}$ corresponding to $\mathrm{CO}$, at $1188-1090 \mathrm{~cm}^{-1}$ corresponding to $\mathrm{CO}$, at $1452-1368 \mathrm{~cm}^{-1}$ corresponding to $\mathrm{COH}$, and at $3000 \mathrm{~cm}^{-1}$ corresponding to $\mathrm{CH}$ [47]. The immobilization of chitosan with different molecular weights was also evaluated by FTIR. It was observed that the functional groups of chitosan, such as the characteristic $\mathrm{NH}$ stretch band of chitosan with a maximum at $3350 \mathrm{~cm}^{-1}$ [48] was identified on the functionalized CS-PLA surfaces. The broad -OH stretching absorption band between 3680 and $2750 \mathrm{~cm}^{-1}$ was also observed, as well as one between 2980 and $2750 \mathrm{~cm}^{-1}$ assigned to aliphatic C-H stretching [48] which corresponds to typical vibrations of chitosan. These results confirmed the immobilization of CS on PLA surfaces. However, no differences between the spectrum of PLA surfaces functionalized with CS with different Mw were identified (Figure 1b).

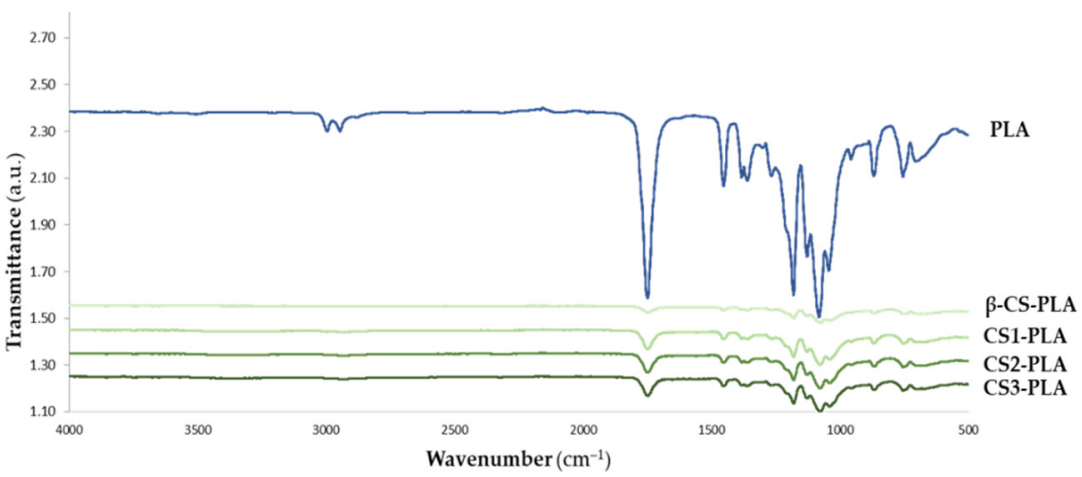

(a)

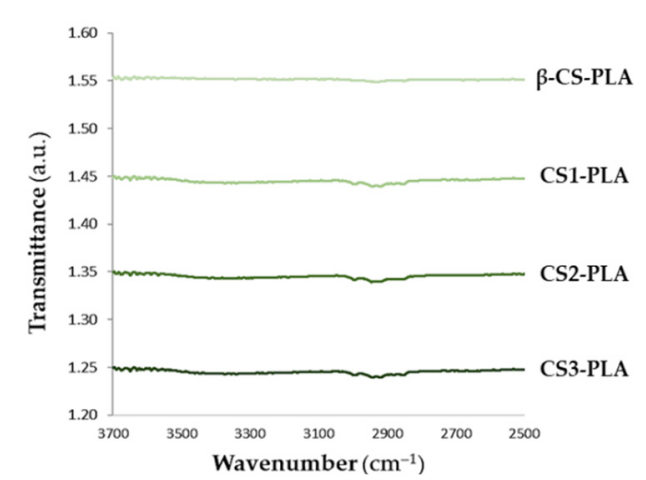

(b)

Figure 1. FTIR spectrum of (a) PLA and CS-PLA surfaces and (b) an inset graphic showing the characteristic bands of CS onto PLA films.

XRD spectroscopy was also performed to prove CS immobilization (Figure S3 in Supplementary Materials). Regarding the PLA film, diffraction peaks at $2 \theta=16.5^{\circ}, 20^{\circ}$, and $22^{\circ}$ were obtained, indicating a crystalline polymer matrix [49]. The CS immobilization triggered a decrease in the intensity peaks [50], confirming the deposition of chitosan on the PLA film. Moreover, different types of chitosan did not impact the XRD pattern.

The surface characterization of CS-PLA films was complemented by scanning electron microscopy (SEM) analysis. This technique allows the evaluation of the morphology of functionalized surfaces, and the distribution of CS and its derivatives onto PLA films. SEM analysis demonstrated the clear homogeneity of PLA surface and the presence of small aggregates on PLA surfaces coated with CS, which probably correspond to insoluble CS material (Figure S4a-c in Supplementary Materials). However, chitosan originated uniform and continuous coatings on the PLA film, as can be observed in the higher magnification micrographs (Figure S4d,e in Supplementary Materials).

\subsection{Antibiofilm Activity of Functionalized Surfaces}

The antibiofilm performance of PLA, $\beta$-CS-PLA, CS1-PLA, CS2-PLA, and CS3-PLA surfaces was evaluated against single- and dual-species biofilms of $S$. aureus and P. aeruginosa for $24 \mathrm{~h}$. The cellular composition of biofilms was determined by counting total, viable, culturable, and VBNC cells (Figure 2). Biofilms were detached from surfaces and the number of culturable cells was determined by colony-forming units (CFU) counting, while the number of total and viable cells was determined by epifluorescence microscopy. In turn, the number of VBNC cells was estimated as the difference between the viable cells and culturable ones. Results were presented as the percentage of biofilm cells compared to the control-PLA film. 


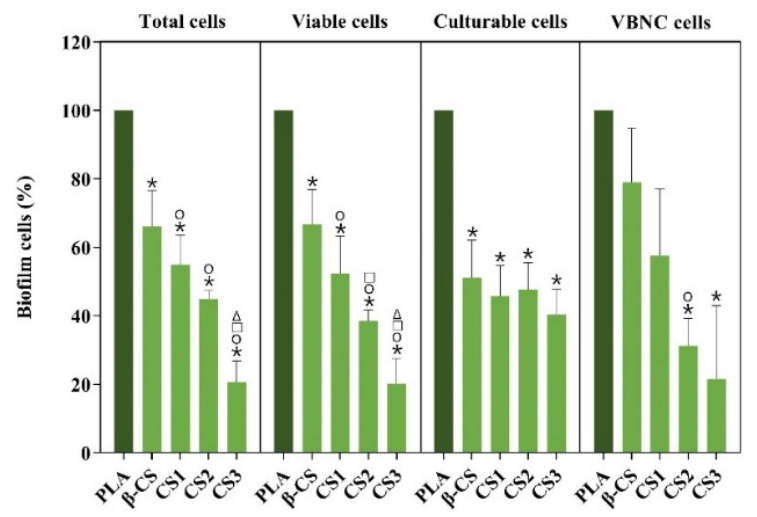

(a)

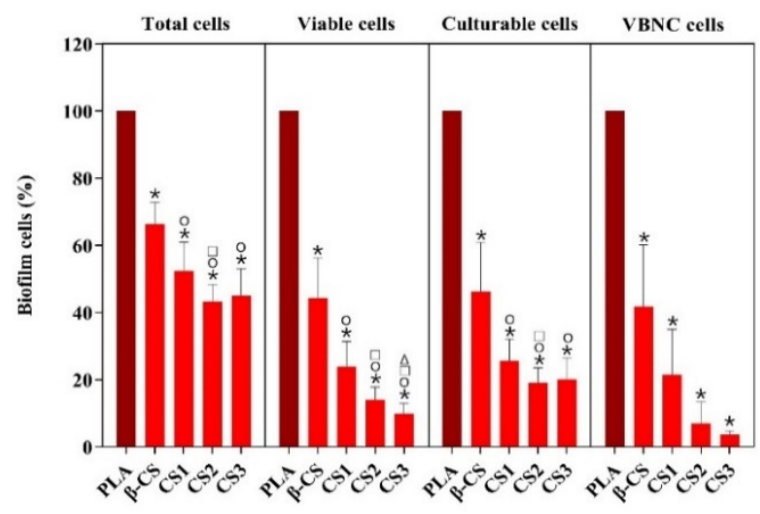

(b)

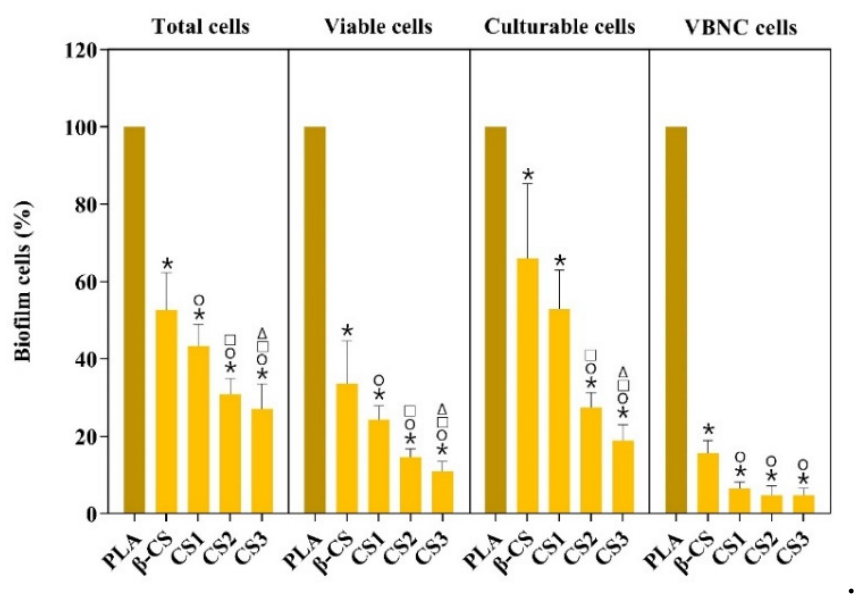

(c)

Figure 2. Percentage of total, viable, culturable, and viable but nonculturable (VBNC) cells for (a) S. aureus, (b) P. aeruginosa, and (c) dual-species biofilms formed during $24 \mathrm{~h}$ on PLA and CS-coated PLA surfaces ( $\beta$-CS, CS1, CS2, and CS3). Differences between functionalized surfaces were evaluated using the nonparametric Mann-Whitney test and represented for $p$-values $<0.05$ by $*, \bigcirc, \square$, and $\Delta$ when compared to PLA, $\beta$-CS-PLA, CS1-PLA, and CS2-PLA, respectively.

The analysis of biofilm cells indicated that $S$. aureus biofilms formed on CS-based surfaces exhibited 33 to $79 \%$ fewer total cells than PLA $(p<0.05)$, being this reduction higher for CS-PLA surfaces of low molecular weight CS (CS2 of $129 \mathrm{kDa}$ and CS3 of $61 \mathrm{kDa}$ ) (Figure 2a). A similar tendency was observed for the number of viable cells, with biofilms formed on CS2- and CS3-PLA surfaces presenting only 39 and 20\% cells $(p<0.05)$, respectively. S. aureus biofilms formed on CS-PLA surfaces also displayed a lower percentage of culturable cells $(40-51 \%)$ compared to PLA $(p<0.05)$. In turn, the percentage of VBNC cells was reduced by 21 to $78 \%$ on CS-coated PLA surfaces, being this effect more pronounced for CS2- and CS3-PLA $(p<0.05)$.

Regarding P. aeruginosa (Figure $2 b$ ), biofilms formed on CS-based surfaces displayed a lower percentage of total (45-66\%), viable (10-44\%), and culturable (20-46\%) cells compared to PLA $(p<0.05)$. Once again, the most effective surfaces were those with low molecular weight CS (CS2 and CS3). Moreover, CS2- and CS3-PLA were able to reduce the percentage of VBNC cells by 93 and $96 \%$, respectively.

The analysis of biofilm cell composition also demonstrated that CS-based surfaces exerted a higher antimicrobial activity against $P$. aeruginosa than $S$. aureus as demonstrated by the percentage of viable, culturable, and VBNC cells (Figure 2a,b).

When evaluating the performance of CS-based surfaces against dual-species biofilms (Figure 2c), results showed that these surfaces presented a lower percentage of total $(27-53 \%)$, viable $(11-34 \%)$, and culturable $(19-66 \%)$ cells compared to PLA $(p<0.05)$. 
In addition, VBNC cells were significantly reduced in CS1-, CS2-, and CS3-PLA surfaces by more than $94 \%$.

The inhibition of dual-species biofilms was also dependent on CS molecular weight. Furthermore, CS-based surfaces yielded a similar antimicrobial effect against $P$. aeruginosa and dual-species biofilms, as confirmed by the percentage of viable, culturable, and VBNC cells. In fact, dual-species biofilms were mostly composed of $P$. aeruginosa (more than 3:4, Figure S5a-e in Supplementary Materials), which may justify a more similar behavior between single-species biofilms of $P$. aeruginosa and mixed biofilms.

The antibiofilm activity of CS-based surfaces against single- and dual-species biofilms of $S$. aureus and $P$. aeruginosa was also evaluated by confocal laser scanning microscopy (CLSM). Figure 3 shows the three-dimensional (3D) structure of single-species biofilms of $S$. aureus and P. aeruginosa developed on PLA (control surface) and PLA surfaces functionalized with different chitosans ( $\beta$-CS, CS1, CS2, and CS3). It is possible to visualize that the $P$. aeruginosa strain formed denser and thicker biofilms (shadow projection on the right of micrographs) than S. aureus, regardless of the surface material. Additionally, the uncoated PLA film (Figure $3 \mathrm{a}, \mathrm{f}$ ) showed the highest biofilm amount when compared to the surfaces functionalized with CS, regardless of the bacterial strain tested.

Looking at the architecture of staphylococcal biofilms (Figure 3a-e), a gradual decrease in biofilm amount and thickness was observed as the CS Mw decreased (from the surface coated with $\beta$-CS of Mw $=294 \mathrm{kDa}$ to the surface with CS3 of Mw $=61 \mathrm{kDa}$ ). This visual inspection was validated through the biofilm biovolume and thickness values estimated from the confocal image analysis (Figure $4 a, b$ ). Indeed, the CS2 and CS3 surfaces containing the two chitosans with lower Mw (129 and $61 \mathrm{kDa}$, respectively) were capable of reducing the S. aureus biovolume and biofilm thickness by on average $78 \%$ and $65 \%$, respectively, when compared to the PLA surface ( $p<0.05$, Figure $4 a, b)$.

Concerning the $P$. aeruginosa single-species biofilms, microscopic images revealed that a reduction in biofilm thickness occurred between the PLA and CS-coated PLA surfaces (shadow projection on the right of Figure $3 \mathrm{f}-\mathrm{j}$ ).

Quantitative data (Figure 4c,d) shows that, on average, CS1 and CS2 decreased the biovolume and thickness of Pseudomonas biofilms by $56 \%$ and $50 \%$, respectively, compared to PLA $(p<0.05)$, while CS3 was the surface with the highest antibiofilm performance, as reported for S. aureus, with reductions of around $66 \%$ for both biofilm parameters $(p<0.05$, Figure $4 \mathrm{c}, \mathrm{d})$.

Figure 5 presents the 3D structure of dual-species biofilms (S. aureus + P. aeruginosa) formed on the different surfaces in order to elucidate the interactive behavior of the strains when co-cultured for $24 \mathrm{~h}$. The first row presents the simultaneous localization of P. aeruginosa (in red) and S. aureus (in green) within the dual-species biofilms (Figure 5a-e), whereas the second row corresponds to the spatial distribution of only S. aureus cells in the same biofilms (Figure 5f-j). As observed for the single-species biofilms of P. aeruginosa, mixed-species biofilms are quite dense and thick on all tested surfaces (shadow projection on the right of Figure 5a-e), and the dominant strain was clearly the Gram-negative bacterium $P$. aeruginosa. A small number of $S$. aureus cells were heterogeneously distributed across surfaces, particularly on CS-based surfaces where the percentage of S. aureus population in the biofilm varied between $21 \%$ and $28 \%$ (Figure S5a-e in Supplementary Materials). When comparing the confocal images of $S$. aureus in single- and dual-species biofilms (Figures $3 \mathrm{a}-\mathrm{e}$ and $5 \mathrm{a}-\mathrm{e}$, respectively), it is noticeable that $S$. aureus colonization was reduced in mixed biofilms. The CLSM study also indicated that the strains were co-located, which means that $P$. aeruginosa and $S$. aureus cells were mixed throughout the biofilm volume (co-aggregation), independently of the tested materials (data not shown). 


\section{S. aureus}

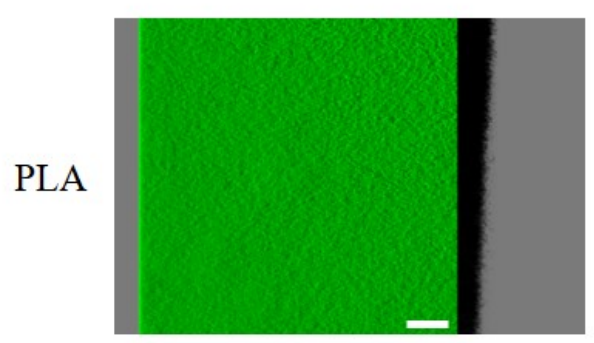

(a)

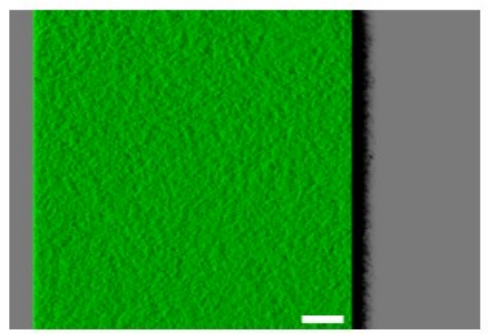

(b)

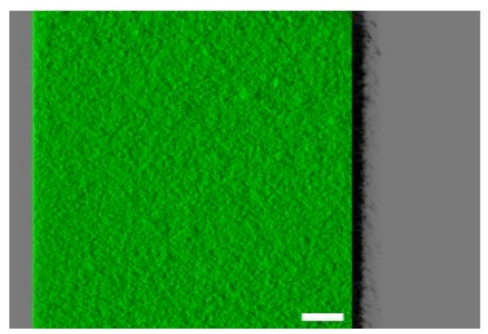

(c)

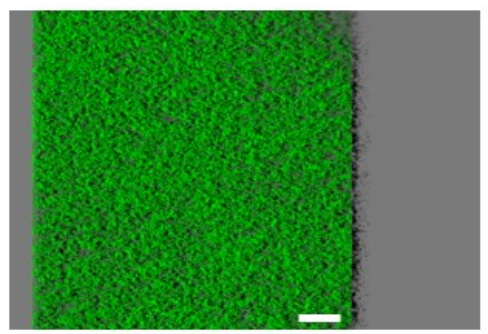

(d)

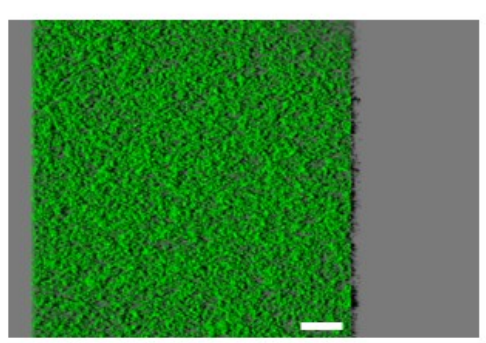

(e)
P. aeruginosa

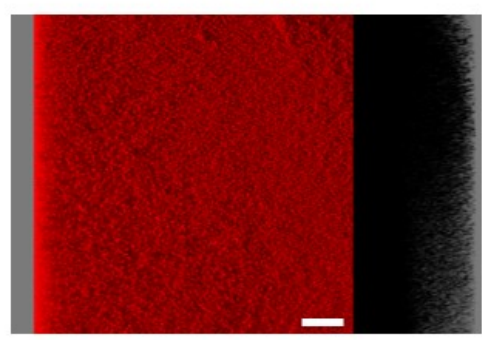

(f)

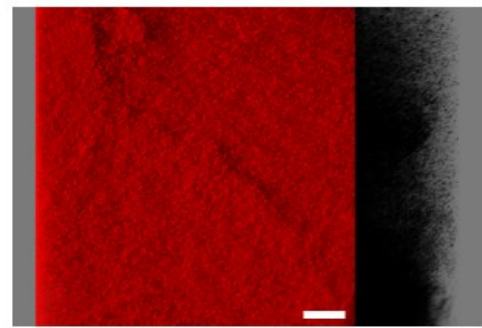

(g)

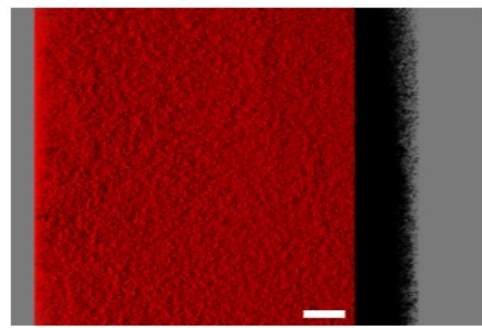

(h)

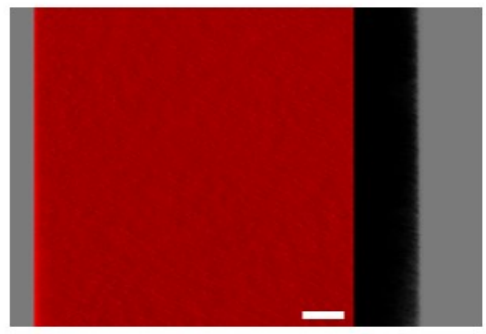

(i)

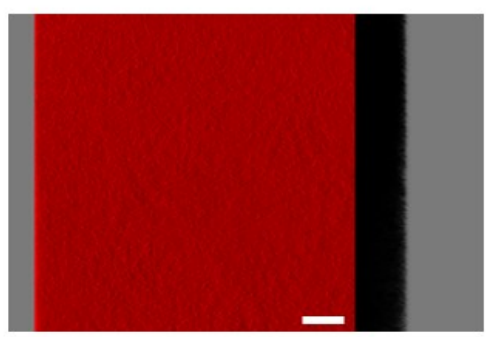

(j)

Figure 3. Single-species biofilms of (a-e) S. aureus and $(\mathbf{f}-\mathbf{j})$ P. aeruginosa developed on PLA and CS-coated PLA surfaces. These representative images were obtained from confocal $z$-stacks using IMARIS software and present an aerial, three-dimensional (3D) view of the biofilms. The shadow on the right represents the vertical projection of the biofilm. Scale bars are $50 \mu \mathrm{m}$. 


\section{S. aureus}

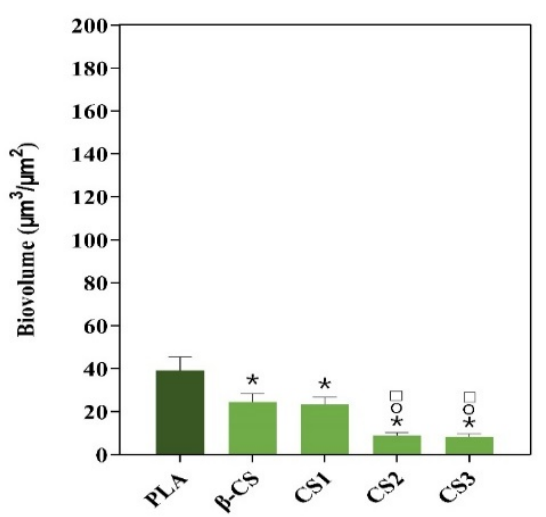

(a)

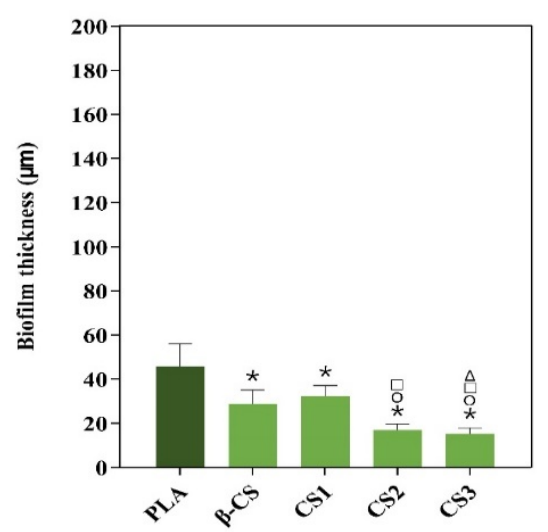

(b)
P. aeruginosa

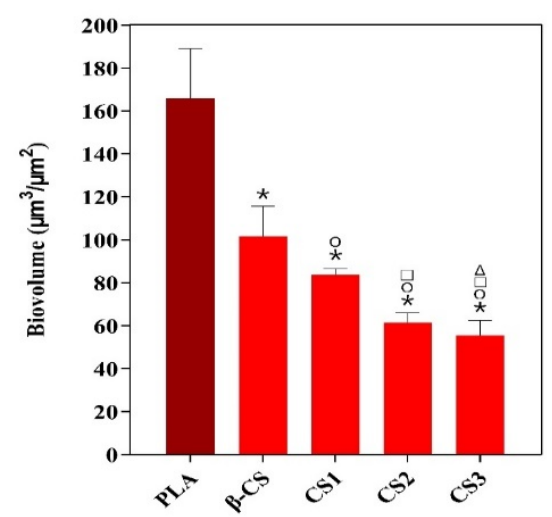

(c)

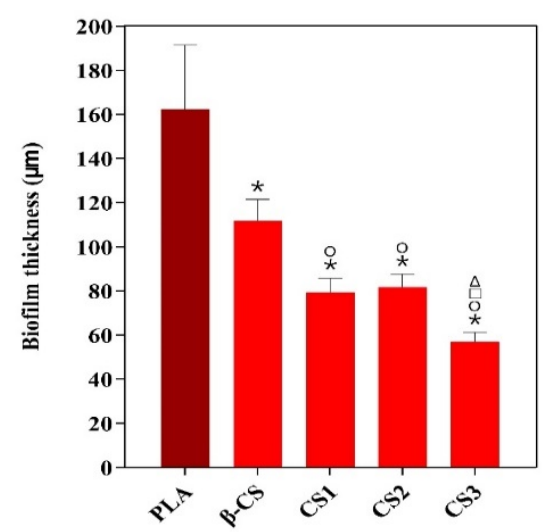

(d)

\section{S. aureus + P. aeruginosa}

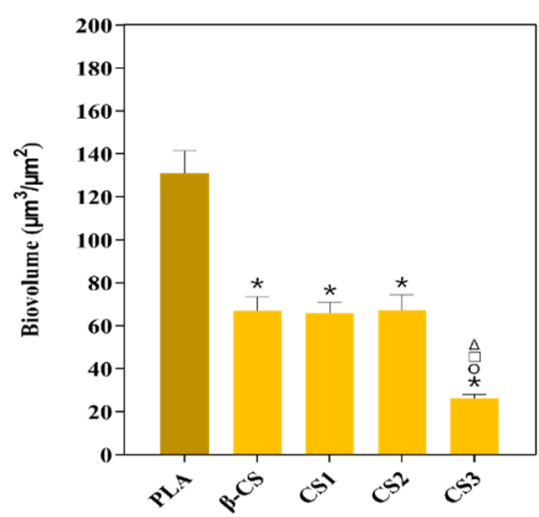

(e)

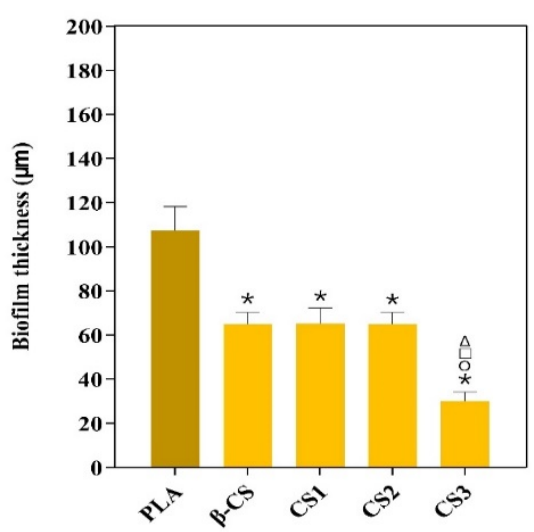

(f)

Figure 4. Biovolumes $(\mathbf{a}, \mathbf{c}, \mathbf{e})$ and thickness $(\mathbf{b}, \mathbf{d}, \mathbf{f})$ of $S$. aureus and P. aeruginosa single-species biofilms, and of dual-species biofilms (S. aureus + P. aeruginosa) on PLA and CS-coated PLA surfaces. These parameters were obtained from confocal image series using the COMSTAT2 tool associated with the ImageJ software. The means \pm standard deviations for three independent experiments are illustrated. Statistical analysis was performed using one-way analysis of variance (ANOVA) and significant differences were represented for $p$-values $<0.05$ by $*, \bigcirc, \square$, and $\Delta$ when compared with PLA, $\beta$-CS, CS1, and CS2, respectively.

Measurements of total biovolume and biofilm thickness of dual-species biofilms (Figure $4 \mathrm{e}, \mathrm{f}$ ) showed that the values of these two parameters were overall between the lower values registered for the single-species biofilms of S. aureus (Figure $4 \mathrm{a}, \mathrm{b}$ ) and the higher values determined for P. aeruginosa biofilms (Figure 4c,d). Furthermore, biofilms developed on CS-based surfaces had on average $57 \%$ less biovolume and $48 \%$ less thickness than on PLA, with the CS3-PLA showing again to be the most efficient surface in inhibiting biofilm formation.

Overall, the antimicrobial activity increase of CS-based surfaces with decreasing chitosan Mw was demonstrated by both biofilm cell composition and biofilm structure through CLSM analysis. 
PLA

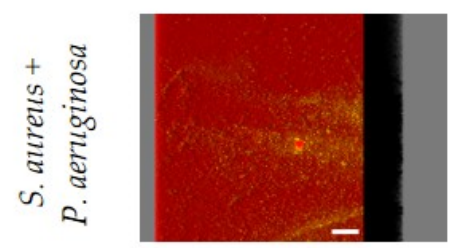

(a)

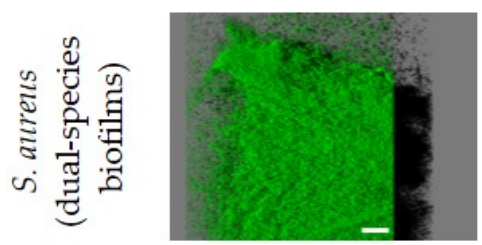

(f)
$\beta$-CS-PLA

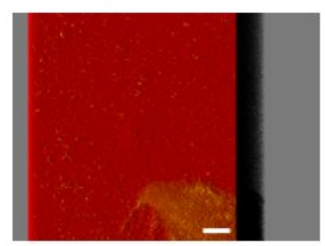

(b)

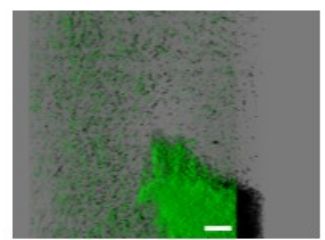

(g)
CS1-PLA

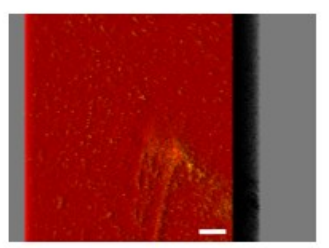

(c)

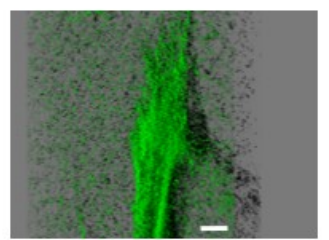

(h)
CS2-PLA

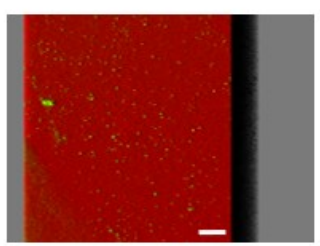

(d)

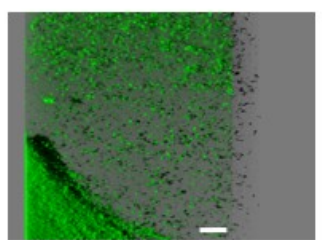

(i)
CS3-PLA

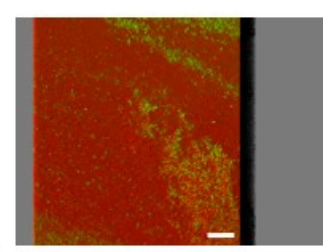

(e)

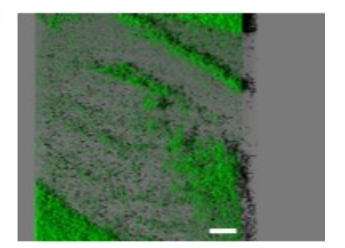

(j)

Figure 5. Dual-species biofilms of S. aureus and P. aeruginosa on PLA and CS-coated PLA surfaces. These representative images were obtained using IMARIS software and show an aerial view of biofilm structures, with the shadow on the right representing the vertical projection of the biofilm. The first row $(\mathbf{a}-\mathbf{e})$ presents the combination of red and green filters $(S$. aureus + P. aeruginosa), while the second row $(\mathbf{f}-\mathbf{j})$ corresponds only to the green filter (S. aureus). Scale bars are $50 \mu \mathrm{m}$.

\section{Discussion}

In this study, CS-based surfaces with different Mw were produced, and their efficacy to inhibit the development of single- and dual-species biofilms of S. aureus and P. aeruginosa was evaluated through the analysis of biofilm cell composition and structure.

Four CS with decreasing Mw, from 294 to $61 \mathrm{kDa}$, were successfully obtained through the enzymatic, alkaline, and salt processing of chitin sourced from Loligo opalescences squid endoskeletons [43] (obtained as a discard from the fishery industry) and immobilized at $0.5 \%(w / v)$ onto PLA films by dip-coating. Most of the commercially available chitin comes from crustaceans shells, where polymeric chains are in antiparallel fashion ( $\alpha$-chitin), while the opposite occurs in other sources such as squid pen ( $\beta$-chitin). Inter- and intramolecular forces are stronger in $\alpha$ - than in $\beta$-chitin, resulting in increased solubility and water-absorbing capacity of squid pen $\beta$-chitin [51].

Since it is known that surface properties influence microbial adhesion and subsequent biofilm formation [45,52], the PLA and CS-coated PLA surfaces were first analyzed concerning their hydrophobicity, surface chemical interactions, and morphology. Results from water contact angles measurement indicated that the immobilization of CS solutions increased the hydrophilicity of PLA surfaces. Other studies also showed that the immobilization of CS molecules improved surface hydrophilicity by increasing the number of polar groups, making bacterial adhesion less favorable [53,54]. In fact, several authors report that bacteria are more likely to attach to hydrophobic than hydrophilic surfaces $[55,56]$, which supports the notion that functionalized CS-PLA surfaces may reduce biofilm formation on IMDs. In addition, the contact angles of CS-PLA surfaces were not dependent on CS molecular weight and their hydrophilic character was maintained across the different CS-based surfaces. Similar results were obtained by Stoleru et al. [47], which demonstrated that chitosan Mw did not affect the wettability of functionalized PLA surfaces.

Concerning surface chemical modifications, FTIR analysis revealed the presence of CS characteristic bands on the spectrum of PLA [47], indicating that CS molecules were successfully immobilized in these films. Moreover, there were no differences in FTIR spectra among different CS-based surfaces, which suggests that molecular weight did not interfere with interactions between CS and the PLA matrix. This result is supported by a previous study developed by Ang et al. [57], showing that the FTIR spectra of medium and low Mw chitosan displayed a similar pattern. 
Lastly, the study of surface morphology by SEM showed that CS-PLA surfaces exhibited a more heterogeneous appearance than the PLA. Indeed, the presence of insoluble CS materials may induce the formation of small aggregates on the surface of functionalized CS-PLA surfaces. As some authors have reported, chitosan has poor solubility [58] and extensive research has been carried out to increase it and extend CS use in a broader range of environmental conditions. Contrary to water contact angles and FTIR results, the CS molecular weight seems to have an impact on surface morphology. In fact, the presence of small aggregates was more notorious for CS-PLA surfaces with high Mw chitosan ( $\beta$-CS of $294 \mathrm{kDa}$ and CS1 of $186 \mathrm{kDa}$ ). According to Peng et al. [59], the functionalization of CS may increase its water solubility, which may explain the higher homogeneity of CS3-PLA surface. Furthermore, other authors have reported that with increasing molecular weight compounds, the reaction between their end-group and the complementary group on the substrate surface becomes less efficient, which may have a significant role in microbial adhesion and cell growth $[32,60]$.

In general, the surface characterization of CS-PLA films revealed that CS was successfully immobilized and that CS molecular weight only impacted its distribution on PLA surfaces.

Besides the surface properties, biofilm development may be influenced by the microorganism type [52]. Thus, the efficacy of CS-coated PLA surfaces to inhibit biofilm formation was assessed against a Gram-positive (S. aureus) and a Gram-negative (P. aeruginosa) bacteria. The analysis of biofilm cell composition showed that CS-based surfaces significantly reduced the number of total, viable, and culturable S. aureus cells by 60 to $80 \%$, revealing their anti-adhesive and antimicrobial properties. The efficacy of CS-coated films to decrease S. aureus biofilm formation and reduce its viability was previously reported $[53,54]$ and corroborated by our results. CS-PLA surfaces were able to reduce the percentage of total, viable, and culturable P. aeruginosa cells by 55 to $90 \%$. Similar results were previously obtained by Kara et al. [54]. The analysis of biofilm structure revealed the efficacy of CS-PLA surfaces to inhibit S. aureus and P. aeruginosa biofilm formation compared to PLA films. In fact, uncoated PLA film showed the highest biofilm amount when compared to the surfaces functionalized with CS.

CS-based surfaces were highly effective in reducing the percentage of VBNC cells, particularly for P. aeruginosa ( $>96 \%$ ). To the best of our knowledge, this is the first study addressing the effect of CS-based surfaces on the reduction of VBNC cells. The VBNC state is an important survival strategy adopted by several bacteria when exposed to unfavorable conditions [61]. Given that VBNC cells are more resistant to antimicrobial therapy and can reinitiate infection when appropriate conditions are established $[17,61]$, our results suggest that CS-PLA surfaces may be beneficial to coat IMDs.

In general, the strong antimicrobial activity of CS-based surfaces against Grampositive and Gram-negative bacteria possibly results from the interaction between positively charged CS molecules and negatively charged cell membranes, which may prevent mass transfer across the membrane and consequently lead to cell death [62]. In addition, it is also likely that CS penetrates cell membranes and binds to DNA, inhibiting protein synthesis [63]. However, the analysis of biofilm cell composition and structure (e.g., biovolume and biofilm thickness) indicates that CS-coated PLA surfaces exerted higher antimicrobial activity against $P$. aeruginosa than $S$. aureus, which may be explained by bacteria surface polarity. The outer membrane of Gram-negative bacteria is essentially composed of lipopolysaccharides containing phosphate and pyrophosphate groups which increase the negative charge density on the bacterial surfaces, leading to higher attraction to the positive CS surfaces compared to $S$. aureus cells [54]. Furthermore, it was possible to observe that the antimicrobial activity of functionalized surfaces increased with the decrease of CS molecular weight, as demonstrated by biofilm cell composition and structure. In fact, results point to the CS2- and CS3-PLA as the most promising surfaces in reducing the number of biofilm cells, biovolume and biofilm thickness, possibly because low $\mathrm{Mw}$ chitosan penetrates the bacterial cell wall more easily due to their reduced size [64]. 
As several studies have shown that mixed biofilms exhibit enhanced resistance compared to single-species biofilms, the antibiofilm performance of functionalized surfaces was also tested against $S$. aureus and P. aeruginosa dual-species biofilms. Data demonstrated that biofilms formed on CS-coated PLA surfaces presented a lower percentage of total, viable and culturable cells than uncoated PLA. These results were supported by biofilm biovolume and thickness analysis. In addition, the presence of VBNC cells was significantly reduced in CS-based surfaces by more than $94 \%$. As with single-species biofilms, the inhibition of mixed biofilms showed the same dependency on CS Mw. Furthermore, CS-based surfaces yielded a similar antimicrobial effect against $P$. aeruginosa and dualspecies biofilms. Other authors also demonstrated that CS-based surfaces were effective in inhibiting both single- and dual-species biofilms [65]. The similar behavior of singlespecies biofilms of $P$. aeruginosa and dual-species biofilms may be related to the strong dominance of $P$. aeruginosa in dual-species biofilms, as demonstrated by cell counting and CLSM analysis. It is possible that P. aeruginosa outcompeted S. aureus from coculture biofilms [66,67], being the growth of dual-species biofilms representative of the growth rate of the Gram-negative bacteria.

Generally, this work demonstrates the potential of CS of low Mw for coating polymeric devices such as IMDs and hinder single- and dual-species biofilm formation by $S$. aureus and P. aeruginosa.

\section{Materials and Methods}

\subsection{Chitosan and Its Derivatives}

Chitosan was isolated from Loligo opalescens squid endoskeletons (pens) through a combination of enzymatic and alkaline treatments following a previously optimized protocol [43]. Briefly, squid pens were milled and deproteinized using a protease (Alcalase from Novozymes, Bagsvaerd, Denmark) to produce chitin. Subsequently, chitin was submitted to $\mathrm{NaOH}$ treatment for conversion into chitosan. The recovered CS ( $\beta$-CS) was sequentially depolymerized through the reaction with sodium nitrite according to the protocol developed by Allan et al. [68] and generated three depolymerized samples (CS1, CS2, and CS3) which were freeze-dried and milled to a fine powder.

The molecular weight of native and depolymerized CS was determined by gel permeation chromatography (GPC) [43]. The degree of acetylation of native CS was estimated through nuclear magnetic resonance (NMR) spectroscopy, from the relationship between acetyl integrals (N-acetyl: NAc and $\mathrm{AcOH}$ ) and the integral sum of $\mathrm{H} 2-\mathrm{H} 6$ protons (glucosamine: GluN and N-acetylglucosamine: GluNAc) [69,70], as shown in Figure S1 (Supplementary Materials). The degree of acetylation was assumed to be virtually the same for native and depolymerized CS as only between 0.1 and $0.3 \%$ of the glycosidic bonds were calculated to be cleaved during hydrolysis, based on the initial degree of acetylation and molecular weight estimations.

\subsection{Surface Functionalization}

Solutions of $\beta$-CS and its three derivatives (CS1, CS2, and CS3) at $0.5 \%(w / v)$ were immobilized onto polylactic acid (PLA) films (Figure S6 in Supplementary Materials). Transparent PLA films with $0.05 \mathrm{~mm}$ of thickness (Goodfellow, UK) were chosen as a substrate because this polymer is commonly used for the construction of IMDs [39]. Table S1 (Supplementary Materials) reports the mechanical, physical, and thermal properties of PLA films.

First, PLA films $(1 \times 1 \mathrm{~cm})$ were submitted to plasma oxygen treatment (Harrick Plasma, PJS-14-0240) at moderate intensity for $15 \mathrm{~min}$ [71] to improve the adhesion of CS molecules. Subsequently, films were coated with the different CS solutions by dip-coating for $15 \mathrm{~min}$ and dried with nitrogen for $5 \mathrm{~min}$ [71]. 


\subsection{Surface Characterization}

\subsubsection{Water Contact Angle Measurement}

The surface hydrophobicity was determined through the measurement of water contact angles by the sessile drop technique in a drop shape analyzer (DSA 100E, Kruss Gmbh, Hamburg, Germany). A water droplet $(2 \mu \mathrm{L})$ was deposited in different locations of the surface and drop images were acquired using a camera connected to the analyzer. Water contact angles were estimated through the circle-fitting method [72]. For each surface, at least ten measurements were performed [73].

\subsubsection{Fourier Transform Infrared Spectroscopy (FTIR)}

FTIR spectra of the functionalized CS-PLA surfaces were evaluated with VERTEX 80v FTIR spectrometer (Bruker, Rheinstetten, Germany) in the wavelength range $4000-400 \mathrm{~cm}^{-1}$ at a resolution of $4 \mathrm{~cm}^{-1}$ and normalized between 0 and 1 , using platinum attenuated total reflection mode (ATR) (Bruker, Rheinstetten, Germany) [74].

\subsubsection{X-ray Diffraction (XRD)}

$X R D$ was used to assess the influence of CS on the crystalline structure of the PLA matrix. The XRD patterns of PLA films with and without chitosan were obtained through a diffractometer (PanAnalytical X Pert PRO MRD system, Malvern, UK). The scanning range varied from $2 \theta=10^{\circ}$ to $50^{\circ}[75]$.

\subsubsection{Scanning Electron Microscopy (SEM)}

The surface topology and the distribution of CS and its derivatives on PLA films were assessed by SEM (Quanta 650 FEG, FEI Company, Hillsboro, OR, USA) with an accelerating voltage of $+5 \mathrm{kV}$ at $500 \times$ and $2500 \times$. Samples were cut, placed on sample holders with double-sided adhesive, and sputtered with a $10 \mathrm{~nm}$ layer of gold [74].

\subsection{Bacteria and Culture Conditions}

The antibiofilm activity of the functionalized surfaces was evaluated using a Staphylococcus aureus reference strain (ATCC 25923) and a mCherry-P. aeruginosa PAO1 strain [76], since these microorganisms are commonly isolated from IAIs [38]. The selection of a mCherry-expressing strain allows the $P$. aeruginosa identification in mixed biofilms.

Bacterial strains preserved at $-80{ }^{\circ} \mathrm{C}$ in Luria-Bertani broth (LB, Thermo Fisher Scientific, Waltham, MA, USA) containing $20 \%(v / v)$ glycerol were spread on plate count agar (PCA, Merck KGaA, Darmstadt, Germany) plates and incubated for $24 \mathrm{~h}$ at $37^{\circ} \mathrm{C}$. Single colonies were collected from agar plates, inoculated in $250 \mathrm{~mL}$ of LB broth and incubated at $37^{\circ} \mathrm{C}, 160 \mathrm{rpm}$ for $16 \pm 2 \mathrm{~h}$. Tetracycline at $1.25 \mathrm{mg} . \mathrm{L}^{-1}$ final concentration was used to select mCherry-P. aeruginosa colonies [76].

The overnight cultures were centrifuged (Eppendorf Centrifuge 5810R, Eppendorf, Hamburg, Germany) at $18{ }^{\circ} \mathrm{C}, 3772 \mathrm{~g}$ for $10 \mathrm{~min}$, and resuspended in fresh LB medium in order to obtain a final suspension with an optical density at $610 \mathrm{~nm}$ of 0.1 , which corresponds to approximately $1 \times 10^{8} \mathrm{CFU} \cdot \mathrm{mL}^{-1}$. Bacterial suspensions of S. aureus and $P$. aeruginosa were directly used to form single-species biofilms, while in the case of dual-species biofilms, they were mixed in a 1:1 ratio.

\subsection{Biofilms Assays}

\subsubsection{Biofilm Formation}

Biofilms were formed in 12-well microtiter plates (VWR International, Carnaxide, Portugal) under static conditions. UV-sterilized surfaces, including the PLA (positive control) and the four functionalized CS surfaces, were fixed on the microplate wells using double-sided adhesive tape and inoculated with $3 \mathrm{~mL}$ of bacterial suspension. In addition, $3 \mathrm{~mL}$ of LB medium was added to the sterilized surfaces to control their sterility through the experiments. Microplates were incubated at $37^{\circ} \mathrm{C}$ for $24 \mathrm{~h}$. 
Biofilm formation experiments were performed in three independent assays, each one with three technical replicates.

\subsubsection{Biofilm Quantification}

After $24 \mathrm{~h}$ of biofilm formation, PLA and CS-based surfaces were detached from microplate wells, dipped in $2 \mathrm{~mL}$ of $8.5 \mathrm{~g} \cdot \mathrm{L}^{-1} \mathrm{NaCl}$ solution and vortexed for $3 \mathrm{~min}$ at maximum power (ZX4, Velp Scientifica) to obtain biofilm cell suspensions. Then, bacterial suspensions were properly diluted and spread on PCA, and incubated overnight at $37^{\circ} \mathrm{C}$. The culturability of biofilm cells was determined by CFU counting $\left(\mathrm{CFU} \cdot \mathrm{cm}^{-2}\right)$. In turn, the viability of biofilm cells was evaluated by staining the biofilm suspension with the Live/Dead ${ }^{\circledR}$ BacLight $^{\mathrm{TM}}$ Bacterial Viability kit (Invitrogen Life Technologies, Alfagene, Portugal) as previously described [77], and analyzing in an epifluorescence microscope (Leica DM LB2, Germany). This staining comprises two fluorescent dyes, the Syto ${ }^{\circledR} 9$ that penetrates all cells and the propidium iodide that penetrates only cells with impaired membranes. A minimum of fifteen fields of view was analyzed using the ImageJ software (version 1.52p, National Institutes of Health, EUA) and the number of total and viable cells was quantified (cells $\cdot \mathrm{cm}^{-2}$ ). In addition, the number of VBNC cells was also determined by the difference between the number of viable and culturable cells [17].

The total, viable, culturable, and VBNCs cells were presented as the percentage of biofilm cells compared to the control (PLA film).

\subsubsection{Confocal Laser Scanning Microscopy (CLSM)}

To assess the biofilm spatial organization on CS-PLA surfaces, single- and dual-species biofilms of $S$. aureus and P. aeruginosa were observed by CSLM [78,79]. First, $24 \mathrm{~h}$ biofilms of $S$. aureus and S. aureus + P. aeruginosa formed on PLA and functionalized surfaces were counterstained with $6 \mu \mathrm{M}$ SYTO ${ }^{\circledR} 9$ (Thermo Fisher Scientific, USA). S. aureus, P. aeruginosa and $S$. aureus $+P$. aeruginosa biofilms were then observed using a $40 \times$ water immersion objective lens (Leica Microsystems, Germany) in an inverted microscope Leica DMI6000-CS with $488 \mathrm{~nm}$ argon and $633 \mathrm{~nm}$ helium-neon lasers. The emitted fluorescence was recorded within the ranges of 500 to $580 \mathrm{~nm}$ and 640 to $730 \mathrm{~nm}$ to collect the SYTO ${ }^{\circledR} 9$ and mCherry emission fluorescence, respectively. A minimum of five stacks of horizontal plane images $(512 \times 512$ pixels, corresponding to $387.5 \mu \mathrm{m} \times 387.5 \mu \mathrm{m})$ with a $z$-step of $1 \mu \mathrm{m}$ was acquired for each biofilm sample.

Three-dimensional (3D) projections of biofilm structures were reconstructed from the CLSM acquisitions using the blend mode of the "Easy 3D" function of IMARIS 9.1 software (Bitplane, Zurich, Switzerland). The plug-in COMSTAT2 associated with the ImageJ software was used to determine the biovolume $\left(\mu \mathrm{m}^{3} \cdot \mu \mathrm{m}^{-2}\right)$ and biofilm thickness $(\mu \mathrm{m})[80]$.

\subsection{Statistical Analysis}

Descriptive statistics were used to calculate the mean and standard or error deviation (SD) for the number of total, viable, culturable and VBNC cells, and biovolume and biofilm thickness. Differences between the number of cells obtained for PLA and CS-PLA ( $\beta$-CS, CS1, CS2, and CS3) surfaces were evaluated using the nonparametric Mann-Whitney test, according to the normality of variables' distribution. In turn, quantitative parameters obtained from confocal microscopy (biovolume and biofilm thickness) were compared using a one-way analysis of variance (ANOVA).

All tests were performed with a confidence level of 95\% ( $p$-value $<0.05)$. Data analysis was performed using the IBM SPSS Statistics version 24.0 for Windows (IBM SPSS, Inc., Chicago, IL, USA).

\section{Conclusions}

In this study, the high antimicrobial and antibiofilm activities of CS-based surfaces were clearly demonstrated against single- and dual-species biofilms of S. aureus ATCC 25923 
and P. aeruginosa PAO1. Although the molecular weight of chitosan did not significantly influence the surface properties of functionalized CS-PLA films, surfaces with low Mw chitosan were more effective in reducing biofilm formation, as demonstrated by both biofilm cell composition and structure. The antimicrobial properties of CS were already described, but the potential of the developed CS-based surfaces to reduce VBNC cells described in our work demonstrates their potential use in clinical applications such as the development of coatings for IMDs.

Supplementary Materials: The following are available online. Figure S1. 1H NMR spectrum (a) and gel permeation eluogram (b) of native chitosan from the pen of Loligo opalescens squid (weight average molecular weight (Mw) $294 \mathrm{kDa}$; polydispersity index (PDI) 1.428); eluograms of depolymerized chitosan: CS1, Mw 186 kDa, PDI 1.349 (c); CS2, Mw 129 kDa, PDI 1.534 (d); CS3, Mw 61 kDa, PDI 1.669 (e). Figure S2. Representative images of water droplets and corresponding contact angles on (a) PLA and CS-coated PLA surfaces: (b) $\beta$-CS-PLA; (c) CS1-PLA; (d) CS2-PLA; and (e) CS3-PLA. The results shown in Table 1 resulted from the average of the angles of several drops of water released onto each of the tested surfaces. Figure S3. X-ray diffraction (XRD) patterns of different types of chitosan immobilized onto PLA surface (CS3 (1), CS2 (2), CS1 (3), and $\beta$-CS (4)) and of PLA film (5). Figure S4. Scanning electron microscopy images of PLA (a) and PLA films coated with the highest $(b, d, \beta$-CS) and lowest (c, e, CS3) molecular weight chitosan at a magnification of $500 \times(a-c)$ and $2500 \times(\mathrm{d}-\mathrm{e})$. The red arrows point to small aggregates visible on CS-PLA surfaces. Figure S5. Proportion of S. aureus (in green) and P. aeruginosa (in red) (a-e) culturable cells and (f-j) biovolume in dual-species biofilms formed on PLA and CS-PLA surfaces. Figure S6. Representative scheme of the functionalization of PLA surfaces with different molecular weights chitosan ( $\beta$-CS, CS1, CS2, and CS3). Table S1. Properties of PLA films from the supplier report.

Author Contributions: Conceptualization, F.J.M.; methodology, M.L., R.T.-S., L.C.G., S.I.F., J.A.V., J.V., M.A.C. and A.I.B.; formal analysis, M.L., R.T.-S. and L.C.G.; investigation, M.L., R.T.-S., L.C.G., S.I.F., J.A.V., J.V., M.A.C. and A.I.B.; resources, F.J.M. and L.P.; data curation, M.L., R.T.-S., L.C.G., M.A.C. and A.I.B.; writing—original draft preparation, R.T.-S., M.L. and L.C.G.; writing-review and editing, F.J.M., J.A.V., J.V., M.A.C. and A.I.B.; supervision, F.J.M. and L.P. All authors have read and agreed to the published version of the manuscript.

Funding: This research was funded by Base Funding-UIDB/00511/2020 of the Laboratory for Process Engineering, Environment, Biotechnology and Energy (LEPABE) funded by national funds through the FCT/MCTES (PIDDAC), and "CVMAR + I-Industrial Innovation and Marine Biotechnology Valorization" project, funded by INTERREG V Espanha Portugal (POCTEP) (0302_CVMAR_I_1_P). The research was also supported by the SurfSAFE project funded by the European Union's Horizon 2020 research and innovation programme under grant agreement No. 952471. R.T.-S. acknowledges the receipt of a junior researcher fellowship from the Project PTDC/BIIBIO/29589/2017-POCI-01-0145-FEDER-029589-funded by FEDER funds through COMPETE2020Programa Operacional Competitividade e Internacionalização (POCI) and by national funds (PIDDAC) through FCT/MCTES. L.C.G. thanks the Portuguese Foundation for Science and Technology (FCT) for the financial support of her work contract through the Scientific Employment StimulusIndividual Call-[CEECIND/01700/2017]. J.A.V. and J.V. also thanks to Xunta de Galicia by Xunta de Galicia (Grupos de Potencial Crecimiento, IN607B 2018/2019) for the financial support.

Institutional Review Board Statement: Not applicable.

Informed Consent Statement: Not applicable.

Data Availability Statement: The data presented in this study are available on request from the corresponding author. The data are not publicly available yet as some data sets are being used for additional publications.

Acknowledgments: Kathryn Whitehead from the Manchester Metropolitan University is acknowledged for providing the P. aeruginosa strain.

Conflicts of Interest: The authors declare no conflict of interest. 


\section{References}

1. Kandi, V.; Vadakedath, S. Implant-associated infections: A review of the safety of cardiac implants. Cureus 2020, 12, e12267.

2. Domb, A.; Khan, W. Focal Controlled Drug Delivery; Springer Science \& Business Media: Boston, MA, USA, $2014 ;$ pp. 33-59.

3. Khatoon, Z.; McTiernan, C.D.; Suuronen, E.J.; Mah, T.F.; Alarcon, E.I. Bacterial biofilm formation on implantable devices and approaches to its treatment and prevention. Heliyon 2018, 4, e01067. [CrossRef] [PubMed]

4. VanEpps, J.S.; Younger, J.G. Implantable device-related infection. Shock 2016, 46, 597-608. [CrossRef]

5. Vinh, D.C.; Embil, J.M. Device-related infections: A review. J. Long Term Eff. Med. Implants 2005, 15, 467-488. [CrossRef]

6. Kuehl, R.; Brunetto, P.S.; Woischnig, A.-K.; Varisco, M.; Rajacic, Z.; Vosbeck, J.; Terracciano, L.; Fromm, K.M.; Khanna, N. Preventing implant-associated infections by silver coating. Antimicrob. Agents Chemother. 2016, 60, 2467-2475. [CrossRef]

7. Darouiche, R.O. Device-associated infections: A macroproblem that starts with microadherence. Clin. Infect. Dis. 2001, 33, 1567-1572. [CrossRef] [PubMed]

8. Hetrick, E.M.; Schoenfisch, M.H. Reducing implant-related infections: Active release strategies. Chem. Soc. Rev. 2006, 35, 780-789. [CrossRef]

9. Arciola, C.R.; Campoccia, D.; Montanaro, L. Implant infections: Adhesion, biofilm formation and immune evasion. Nat. Rev. Microbiol. 2018, 16, 397-409. [CrossRef] [PubMed]

10. Yu, J.; Jiang, F.; Zhang, F.; Hamushan, M.; Du, J.; Mao, Y.; Wang, Q.; Han, P.; Tang, J.; Shen, H. Thermonucleases contribute to Staphylococcus aureus biofilm formation in implant-associated infections-a redundant and complementary story. Front. Microbiol. 2021, 12, 1631. [CrossRef]

11. Renz, N.; Trebse, R.; Akgün, D.; Perka, C.; Trampuz, A. Enterococcal periprosthetic joint infection: Clinical and microbiological findings from an 8-year retrospective cohort study. BMC Infect. Dis. 2019, 19, 1083. [CrossRef]

12. Crémet, L.; Broquet, A.; Brulin, B.; Jacqueline, C.; Dauvergne, S.; Brion, R.; Asehnoune, K.; Corvec, S.; Heymann, D.; Caroff, N. Pathogenic potential of Escherichia coli clinical strains from orthopedic implant infections towards human osteoblastic cells. Pathog. Dis. 2015, 73, ftv065. [CrossRef]

13. Cerioli, M.; Batailler, C.; Conrad, A.; Roux, S.; Perpoint, T.; Becker, A.; Triffault-Fillit, C.; Lustig, S.; Fessy, M.-H.; Laurent, F.; et al. Pseudomonas aeruginosa implant-associated bone and joint infections: Experience in a regional reference center in France. Front. Med. 2020, 7, 513242. [CrossRef]

14. Ramage, G.; Martínez, J.P.; López-Ribot, J.L. Candida biofilms on implanted biomaterials: A clinically significant problem. FEMS Yeast Res. 2006, 6, 979-986. [CrossRef]

15. Zhu, Z.; Wang, Z.; Li, S.; Yuan, X. Antimicrobial strategies for urinary catheters. J. Biomed. Mater. Res. A 2019, 107, 445-467. [CrossRef] [PubMed]

16. Costerton, J.W.; Stewart, P.S.; Greenberg, E.P. Bacterial biofilms: A common cause of persistent infections. Science 1999, 284, 1318-1322. [CrossRef] [PubMed]

17. Li, L.; Mendis, N.; Trigui, H.; Oliver, J.D.; Faucher, S.P. The importance of the viable but non-culturable state in human bacterial pathogens. Front. Microbiol. 2014, 5, 258. [CrossRef] [PubMed]

18. Oliver, J.D. Recent findings on the viable but nonculturable state in pathogenic bacteria. FEMS Microbiol. Rev. 2010, 34, 415-425. [CrossRef] [PubMed]

19. Penesyan, A.; Gillings, M.; Paulsen, I.T. Antibiotic discovery: Combatting bacterial resistance in cells and in biofilm communities. Molecules 2015, 20, 5286-5298. [CrossRef]

20. Adlhart, C.; Verran, J.; Azevedo, N.F.; Olmez, H.; Keinänen-Toivola, M.M.; Gouveia, I.; Melo, L.F.; Crijns, F. Surface modifications for antimicrobial effects in the healthcare setting: A critical overview. J Hosp. Infect. 2018, 99, 239-249. [CrossRef] [PubMed]

21. Oyatogun, G.M.; Esan, T.A.; Akpan, E.I.; Adeosun, S.O.; Popoola, A.P.I.; Imasogie, B.I.; Soboyejo, W.O.; Afonja, A.A.; Ibitoye, S.A.; Abere, V.D.; et al. Chapter 11-Chitin, chitosan, marine to market. In Handbook of Chitin and Chitosan; Gopi, S., Thomas, S., Pius, A., Eds.; Elsevier: Amsterdam, The Netherlands, 2020; pp. 341-381.

22. Gafri, H.F.S.; Mohamed Zuki, F.; Aroua, M.K.; Hashim, N.A. Mechanism of bacterial adhesion on ultrafiltration membrane modified by natural antimicrobial polymers (chitosan) and combination with activated carbon (PAC). Rev. Chem. Eng. 2019, 35, 421-443. [CrossRef]

23. Younes, I.; Rinaudo, M. Chitin and chitosan preparation from marine sources. Structure, properties and applications. Mar. Drugs 2015, 13, 1133-1174. [CrossRef] [PubMed]

24. Yi, H.; Wu, L.Q.; Bentley, W.E.; Ghodssi, R.; Rubloff, G.W.; Culver, J.N.; Payne, G.F. Biofabrication with chitosan. Biomacromolecules 2005, 6, 2881-2894. [CrossRef]

25. D'Almeida, M.; Attik, N.; Amalric, J.; Brunon, C.; Renaud, F.; Abouelleil, H.; Toury, B.; Grosgogeat, B. Chitosan coating as an antibacterial surface for biomedical applications. PLOS ONE 2017, 12, e0189537.

26. Tikhonov, V.E.; Stepnova, E.A.; Babak, V.G.; Yamskov, I.A.; Palma-Guerrero, J.; Jansson, H.-B.; Lopez-Llorca, L.V.; Salinas, J.; Gerasimenko, D.V.; Avdienko, I.D.; et al. Bactericidal and antifungal activities of a low molecular weight chitosan and its N-/2(3)-(dodec-2-enyl)succinoyl/-derivatives. Carbohydr. Polym. 2006, 64, 66-72. [CrossRef]

27. Chandrasekaran, M.; Kim, K.D.; Chun, S.C. Antibacterial activity of chitosan nanoparticles: A review. Processes 2020, 8, 1173. [CrossRef]

28. Li, Z.; Yang, F.; Yang, R. Synthesis and characterization of chitosan derivatives with dual-antibacterial functional groups. Int. J. Biol. Macromol. 2015, 75, 378-387. [CrossRef] [PubMed] 
29. Hosseinnejad, M.; Jafari, S.M. Evaluation of different factors affecting antimicrobial properties of chitosan. Int. J. Biol. Macromol. 2016, 85, 467-475. [CrossRef]

30. Chung, Y.C.; Chen, C.Y. Antibacterial characteristics and activity of acid-soluble chitosan. Bioresour. Technol. 2008, 99, 2806-2814. [CrossRef] [PubMed]

31. Kong, M.; Chen, X.G.; Xing, K.; Park, H.J. Antimicrobial properties of chitosan and mode of action: A state of the art review. Int. J. Food. Microbiol. 2010, 144, 51-63. [CrossRef]

32. Lishchynskyi, O.; Stetsyshyn, Y.; Raczkowska, J.; Awsiuk, K.; Orzechowska, B.; Abalymov, A.; Skirtach, A.G.; Bernasik, A.; Nastyshyn, S.; Budkowski, A. Fabrication and impact of fouling-reducing temperature-responsive POEGMA coatings with embedded $\mathrm{CaCO}_{3}$ nanoparticles on different cell lines. Materials 2021, 14, 1417. [CrossRef] [PubMed]

33. Cobrado, L.; Azevedo, M.M.; Silva-Dias, A.; Ramos, J.P.; Pina-Vaz, C.; Rodrigues, A.G. Cerium, chitosan and hamamelitannin as novel biofilm inhibitors? J. Antimicrob. Chemother. 2012, 67, 1159-1162. [CrossRef]

34. Cobrado, L.; Silva-Dias, A.; Azevedo, M.M.; Pina-Vaz, C.; Rodrigues, A.G. In vivo antibiofilm effect of cerium, chitosan and hamamelitannin against usual agents of catheter-related bloodstream infections. J. Antimicrob. Chemother. 2013, 68, 126-130. [CrossRef]

35. Mendoza, G.; Regiel-Futyra, A.; Tamayo, A.; Monzon, M.; Irusta, S.; de Gregorio, M.A.; Kyzioł, A.; Arruebo, M. Chitosan-based coatings in the prevention of intravascular catheter-associated infections. J. Biomater. Appl. 2018, 32, 725-737. [CrossRef] [PubMed]

36. Campana, R.; Casettari, L.; Ciandrini, E.; Illum, L.; Baffone, W. Chitosans inhibit the growth and the adhesion of Klebsiella pneumoniae and Escherichia coli clinical isolates on urinary catheters. Int. J. Antimicrob. Agents. 2017, 50, 135-141. [CrossRef]

37. Campana, R.; Biondo, F.; Mastrotto, F.; Baffone, W.; Casettari, L. Chitosans as new tools against biofilms formation on the surface of silicone urinary catheters. Int. J. Biol. Macromol. 2018, 118, 2193-2200. [CrossRef] [PubMed]

38. Tande, A.J.; Patel, R. Prosthetic Joint Infection. Clin. Microbiol. Rev. 2014, 27, 302. [CrossRef]

39. Rajendra, P.P.; Sunil, U.T.; Suresh, U.S.; Jalinder, T.T.; Abraham, J.D. Biomedical applications of poly(Lactic Acid). Recent Pat. Regen. Med. 2014, 4, 40-51.

40. da Silva, D.; Kaduri, M.; Poley, M.; Adir, O.; Krinsky, N.; Shainsky-Roitman, J.; Schroeder, A. Biocompatibility, biodegradation and excretion of polylactic acid (PLA) in medical implants and theranostic systems. Chem. Eng. J. 2018, 340, 9-14. [CrossRef]

41. Rebelo, R.; Fernandes, M.; Fangueiro, R. Biopolymers in medical implants: A brief review. Procedia Eng. 2017, 200, 236-243. [CrossRef]

42. Scaffaro, R.; Lopresti, F.; Marino, A.; Nostro, A. Antimicrobial additives for poly(lactic acid) materials and their applications: Current state and perspectives. Appl. Microbiol. Biotechnol. 2018, 102, 7739-7756. [CrossRef]

43. Vázquez, J.A.; Ramos, P.; Valcarcel, J.; Antelo, L.T.; Novoa-Carballal, R.; Reis, R.L.; Pérez-Martín, R.I. An integral and sustainable valorisation strategy of squid pen by-products. J. Clean. Prod. 2018, 201, 207-218. [CrossRef]

44. Zheng, S.; Bawazir, M.; Dhall, A.; Kim, H.-E.; He, L.; Heo, J.; Hwang, G. Implication of surface properties, bacterial motility, and hydrodynamic conditions on bacterial surface sensing and their initial adhesion. Front Bioeng. Biotechnol. 2021, 9, 82. [CrossRef]

45. Spengler, C.; Nolle, F.; Mischo, J.; Faidt, T.; Grandthyll, S.; Thewes, N.; Koch, M.; Müller, F.; Bischoff, M.; Klatt, M.A.; et al. Strength of bacterial adhesion on nanostructured surfaces quantified by substrate morphometry. Nanoscale 2019, 11, 19713-19722. [CrossRef] [PubMed]

46. Ma, Y.; Cao, X.; Feng, X.; Ma, Y.; Zou, H. Fabrication of super-hydrophobic film from PMMA with intrinsic water contact angle below $90^{\circ}$. Polymer 2007, 48, 7455-7460. [CrossRef]

47. Stoleru, E.; Dumitriu, R.P.; Munteanu, B.S.; Zaharescu, T.; Tănase, E.E.; Mitelut, A.; Ailiesei, G.-L.; Vasile, C. Novel procedure to enhance PLA surface properties by chitosan irreversible immobilization. Appl. Surf. Sci. 2016, 367, 407-417. [CrossRef]

48. Kaya, M.; Khadem, S.; Cakmak, Y.S.; Mujtaba, M.; Ilk, S.; Akyuz, L.; Salaberria, A.M.; Labidi, J.; Abdulqadir, A.H.; Deligöz, E. Antioxidative and antimicrobial edible chitosan films blended with stem, leaf and seed extracts of Pistacia terebinthus for active food packaging. RSC Adv. 2018, 8, 3941-3950. [CrossRef]

49. Cardoso, E.; Parra, D.F.; Scagliusi, S.R.; Sales, R.M.; Caviquioli, F.; Lugao, A.B. Study of Bio-Based Foams Prepared from PBAT/PLA Reinforced with Bio-Calcium Carbonate and Compatibilized with Gamma Radiation. In Use of Gamma Radiation Techniques in Peaceful Applications; Almayah, B.A., Ed.; IntechOpen: London, UK, 2019.

50. Julkapli, N.M.; Ahmad, Z.; Akil, H.M. X-Ray Diffraction Studies of Cross Linked Chitosan With Different Cross Linking Agents For Waste Water Treatment Application. AIP Conf. Proc. 2010, 1202, 106-111.

51. Vázquez, J.A.; Noriega, D.; Ramos, P.; Valcarcel, J.; Novoa-Carballal, R.; Pastrana, L.; Reis, R.L.; Pérez-Martín, R.I. Optimization of high purity chitin and chitosan production from Illex argentinus pens by a combination of enzymatic and chemical processes. Carbohydr. Polym. 2017, 174, 262-272. [CrossRef]

52. Zhang, X.; Zhang, Q.; Yan, T.; Jiang, Z.; Zhang, X.; Zuo, Y.Y. Quantitatively predicting bacterial adhesion using surface free energy determined with a spectrophotometric method. Environ. Sci. Technol. 2015, 49, 6164-6171. [CrossRef] [PubMed]

53. Bulwan, M.; Wójcik, K.; Zapotoczny, S.; Nowakowska, M. Chitosan-based ultrathin films as antifouling, anticoagulant and antibacterial protective coatings. J. Biomater. Sci. Polym. Ed. 2012, 23, 1963-1980. [CrossRef]

54. Kara, F.; Aksoy, E.A.; Yuksekdag, Z.; Hasirci, N.; Aksoy, S. Synthesis and surface modification of polyurethanes with chitosan for antibacterial properties. Carbohydr. Polym. 2014, 112, 39-47. [CrossRef]

55. Lorenzetti, M.; Dogša, I.; Stošicki, T.; Stopar, D.; Kalin, M.; Kobe, S.; Novak, S. The Influence of Surface Modification on Bacterial Adhesion to Titanium-Based Substrates. ACS Appl. Mater. Interfaces 2015, 7, 1644-1651. [CrossRef] [PubMed] 
56. Di Ciccio, P.; Vergara, A.; Festino, A.R.; Paludi, D.; Zanardi, E.; Ghidini, S.; Ianieri, A. Biofilm formation by Staphylococcus aureus on food contact surfaces: Relationship with temperature and cell surface hydrophobicity. Food Control 2015, 50, 930-936. [CrossRef]

57. Ang, L.F.; Por, L.Y.; Yam, M.F. Study on different molecular weights of chitosan as an immobilization matrix for a glucose biosensor. PLoS ONE 2013, 8, e70597. [CrossRef] [PubMed]

58. Liu, X.F.; Guan, Y.L.; Yang, D.Z.; Li, Z.; de Yao, K. Antibacterial action of chitosan and carboxymethylated chitosan. J. Appl. Polym. Sci. 2001, 79, 1324-1335.

59. Peng, Z.-X.; Wang, L.; Du, L.; Guo, S.-R.; Wang, X.-Q.; Tang, T.-T. Adjustment of the antibacterial activity and biocompatibility of hydroxypropyltrimethyl ammonium chloride chitosan by varying the degree of substitution of quaternary ammonium. Carbohydr. Polym. 2010, 81, 275-283. [CrossRef]

60. Stetsyshyn, Y.; Raczkowska, J.; Harhay, K.; Gajos, K.; Melnyk, Y.; Dąbczyński, P.; Shevtsova, T.; Budkowski, A. Temperatureresponsive and multi-responsive grafted polymer brushes with transitions based on critical solution temperature: Synthesis, properties, and applications. Colloid Polym. Sci. 2021, 299, 363-383. [CrossRef]

61. Liao, H.; Jiang, L.; Zhang, R. Induction of a viable but non-culturable state in Salmonella Typhimurium by thermosonication and factors affecting resuscitation. FEMS Microbiol. Lett. 2018, 365, fnx249. [CrossRef] [PubMed]

62. Kong, M.; Chen, X.G.; Liu, C.S.; Liu, C.G.; Meng, X.H.; Yu, L.J. Antibacterial mechanism of chitosan microspheres in a solid dispersing system against E. coli. Colloids Surf. B Biointerfaces 2008, 65, 197-202. [CrossRef] [PubMed]

63. Sudarshan, N.R.; Hoover, D.G.; Knorr, D. Antibacterial action of chitosan. Food Biotech. 1992, 6, 257-272. [CrossRef]

64. Phan, T.T.V.; Phan, D.T.; Cao, X.T.; Huynh, T.C.; Oh, J. Roles of chitosan in green synthesis of metal nanoparticles for biomedical applications. Nanomaterials 2021, 11, 273. [CrossRef]

65. Tan, Y.; Leonhard, M.; Moser, D.; Ma, S.; Schneider-Stickler, B. Inhibition of mixed fungal and bacterial biofilms on silicone by carboxymethyl chitosan. Colloids Surf. B Biointerfaces 2016, 148, 193-199. [CrossRef]

66. Baldan, R.; Cigana, C.; Testa, F.; Bianconi, I.; De Simone, M.; Pellin, D.; Di Serio, C.; Bragonzi, A.; Cirillo, D.M. Adaptation of Pseudomonas aeruginosa in Cystic Fibrosis airways influences virulence of Staphylococcus aureus in vitro and murine models of co-infection. PLoS ONE 2014, 9, e89614. [CrossRef] [PubMed]

67. Filkins, L.M.; Graber, J.A.; Olson, D.G.; Dolben, E.L.; Lynd, L.R.; Bhuju, S.; O’Toole, G.A. Coculture of Staphylococcus aureus with Pseudomonas aeruginosa drives S. aureus towards fermentative metabolism and reduced viability in a cystic fibrosis model. J. Bacteriol. 2015, 197, 2252-2264. [CrossRef] [PubMed]

68. Allan, G.G.; Peyron, M. Molecular weight manipulation of chitosan. I: Kinetics of depolymerization by nitrous acid. Carbohydr. Res. 1995, 277, 257-272. [CrossRef]

69. Fernandez-Megia, E.; Novoa-Carballal, R.; Quiñoá, E.; Riguera, R. Optimal routine conditions for the determination of the degree of acetylation of chitosan by 1H-NMR. Carbohydr. Pol. 2005, 61, 155-161. [CrossRef]

70. Novoa-Carballal, R.; Fernandez-Megia, E.; Riguera, R. Dynamics of chitosan by 1H NMR relaxation. Biomacromolecules 2010, 11, 2079-2086. [CrossRef]

71. Pinheiro, A.; Bourbon, A.; Quintas, M.; Coimbra, M.; Vicente, A. K-carrageenan/chitosan nanolayered coating for controlled release of a model bioactive compound. Innov. Food Sci. Emerg. Technol. 2012, 16, 227-232. [CrossRef]

72. Bateni, A.; Susnar, S.S.; Amirfazli, A.; Neumann, A.W. A high-accuracy polynomial fitting approach to determine contact angles Colloids Surf. A Physicochem. Eng. Asp. 2003, 219, 215-231. [CrossRef]

73. Martins, V.D.F.; Cerqueira, M.A.; Fuciños, P.; Garrido-Maestu, A.; Curto, J.M.R.; Pastrana, L.M. Active bi-layer cellulose-based films: Development and characterization. Cellulose 2018, 25, 6361-6375. [CrossRef]

74. Costa, M.J.; Pastrana, L.M.; Teixeira, J.A.; Sillankorva, S.M.; Cerqueira, M.A. Characterization of PHBV films loaded with FO1 bacteriophage using polyvinyl alcohol-based nanofibers and coatings: A comparative study. Innov. Food Sci. Emerg. Technol. 2021, 69, 102646. [CrossRef]

75. Martins, A.J.; Silva, P.; Maciel, F.; Pastrana, L.M.; Cunha, R.L.; Cerqueira, M.A.; Vicente, A.A. Hybrid gels: Influence of oleogel/hydrogel ratio on rheological and textural properties. Food. Res. Int. 2019, 116, 1298-1305. [CrossRef]

76. El Mohtadi, M. Effect of Estrogen on Host-Pathogen Interactions in ex vivo and in vitro Models of the Inflammatory Phase of Age-Related Impaired Healing. Ph.D. Thesis, Manchester Metropolitan University, Manchester, UK, September 2019.

77. Gomes, L.C.; Silva, L.N.; Simões, M.; Melo, L.F.; Mergulhão, F.J. Escherichia coli adhesion, biofilm development and antibiotic susceptibility on biomedical materials. J. Biomed. Mater. Res. A 2015, 103, 1414-1423. [CrossRef]

78. Alves, P.; Gomes, L.C.; Vorobii, M.; Rodriguez-Emmenegger, C.; Mergulhão, F.J. The potential advantages of using a poly(HPMA) brush in urinary catheters: Effects on biofilm cells and architecture. Colloids Surf. B 2020, 191, 110976. [CrossRef] [PubMed]

79. Gomes, L.C.; Deschamps, J.; Briandet, R.; Mergulhão, F.J. Impact of modified diamond-like carbon coatings on the spatial organization and disinfection of mixed-biofilms composed of Escherichia coli and Pantoea agglomerans industrial isolates. Int. J. Food Microbiol. 2018, 277, 74-82. [CrossRef]

80. Heydorn, A.; Nielsen, A.T.; Hentzer, M.; Sternberg, C.; Givskov, M.; Ersbøll, B.K.; Molin, S. Quantification of biofilm structures by the novel computer program COMSTAT. Microbiology 2000, 146, 2395-2407. [CrossRef] [PubMed] 